\title{
DERECHO APLICABLE AL FONDO DE LA CONTROVERSIA EN ARBITRAJES SURGIDOS DE TRATADOS DE INVERSIÓN
}

\author{
APPLICABLE LAW TO THE MERITS OF INVESTMENT TREATIES DISPUTES.
}

Francisco Endara Flores ${ }^{1}$

\begin{abstract}
Resumen
En este trabajo se analizará cuál es el derecho aplicable al fondo de la controversia de un arbitraje surgido de un Tratado de Inversiones. A lo largo del artículo se tratará de demostrar que la fuente primaria aplicable al fondo de la controversia, será el mismo Tratado de Inversión, seguido por un análisis del rol que tendrá el derecho local al momento de resolver la controversia. Lo mismo se hará respecto al resto de normas del derecho internacional y la manera en como dichas normas se integran para ser aplicadas por los árbitros al momento de resolver la controversia.
\end{abstract}

Palabras clave: Arbitraje, derecho aplicable, tratados de inversiones, derecho local, lex specialis.

\begin{abstract}
In the present work I will analyze the law applicable to merits of an investment dispute originated under an Investmnet treaty, through out the article it will be established that the proper law to resolve that dispute it is the investment treaty itself. Although as it its discuss here, municipal law plays some role in that matter, and finally $i$ will analyze what type of rol international law plays, and how the rules of international law had been applied by international tribunals.
\end{abstract}

Key words: Arbitration, investment treaty, appicable law, lex specialis, municipal law

Abogado Summa Cum Laude, Facultad de Jurisprudencia de la Universidad San Francisco de Quito. Con Minor o Sub Especialización en Arbitraje Comercial Internacional de la American Universtity, en Washington. Correo: francisco.endara@pmintl.com 


\section{Introducción}

En el presente trabajo se analizará el derecho aplicable al fondo de la controversia o derecho sustantivo. Habiendo realizado esta precisión, se empezará esta sección por mencionar que el derecho aplicable a las controversias entre inversionistas extranjeros y Estados receptores difiere según el instrumento bajo el cual surja dicha controversia. Porque si la controversia con el Estado Receptor se origina bajo el amparo de las disposiciones de un Tratado de Inversión, en adelante TI, tendrá un derecho aplicable distinto a las controversias que surjan de un contrato o de la legislación local.

Para estos últimos casos, el derecho aplicable al fondo de la controversia sería el que las partes hayan establecido o determinado (sea en el mismo contrato de inversión o en la legislación local); y a falta de este se establecerá según las reglas del Centro de Arbitraje al cual las partes decidieron someter su controversia.

Por ejemplo, si las partes acordaron que su controversia sea resuelta por un tribunal arbitral $\mathrm{CIADI}^{2}$, la regla aplicable para el fondo de dicha controversia será el artículo $42^{3}$ del Convenio CIADI, y más específicamente el artículo 42 (1) del Convenio CIADI, que se refiere a la ley aplicable a la controversia. Este artículo permite, que los tribunales arbitrales CIADI, "en ausencia de acuerdo de las partes (...) apliquen el derecho doméstico pertinente y aquellas normas de Derecho Internacional que pudieran ser aplicables" ${ }^{4}$. Los autores del Convenio CIADI contemplaron, entre otras posibilidades ${ }^{5}$, que el Derecho Internacional sea aplicado, para complementar al derecho local.

Producto de dicha concepción es que los primeros arbitrajes surgidos en el sistema $\mathrm{CIADI}^{6}$, sugieren que "el único rol del Derecho Internacional bajo esta provisión

\footnotetext{
Centro Internacional de Arreglo de Diferencias Relativas a Inversiones.

3 Cuyo texto dice:

"(1) El Tribunal decidirá la diferencia de acuerdo con las normas de derecho acordadas por las partes. A falta de acuerdo, el Tribunal aplicará la legislación del Estado que sea parte en la diferencia, incluyendo sus normas de Derecho Internacional privado, y aquellas normas de Derecho Internacional que pudieren ser aplicables.

(2) El Tribunal no podrá eximirse de fallar so pretexto de silencio u oscuridad de la ley.

(3) Las disposiciones de los precedentes apartados de este Artículo no impedirán al Tribunal, si las partes así lo acuerdan, decidir la diferencia ex aequo et bono". Artículo 42 del Convenio CIADI. [consultado el 16 de octubre de 2009]. Disponible en la World Wide Web: http://icsid.worldbank.org/ICSID/ StaticFiles/basicdoc-spa/partA-chap04.htm;

4 Parra, Alberto, "Applicable Law in Investor- State Arbitration", Transnational Dispute Management, [on line], vol.6, issue 1, Marzo, 2009, p. 5. [consultado 30 de noviembre de 2009]. Disponible en la World Wide Web: www.transnational-dispute-management.com

6 Estos arbitrajes no surgieron de un TI, es más, ni se discutió la vulneración de las disposiciones del mismo, sino que fueron reclamos contractuales. Entre estas decisiones podemos encontrar por ejemplo, el caso Klöckner v. Cameroon, Decision on Annulment, 3 May 1985, 2 ICSID Reports 95 at $\uparrow 144$,
}

5 Idem 
sería únicamente para llenar vacíos [o lagunas] en el Derecho del Estado receptor o para corregir las inconsistencias entre el Derecho local y el Derecho Internacional"7.

Sin embargo, por el propósito del presente trabajo, se tratará el derecho aplicable a las controversias surgidas de un $\mathrm{Tl}^{8}$ y no respecto del resto de instrumentos, como un contrato de inversión o la legislación local.

\section{El tratado como fuente primaria aplicable al fondo}

El derecho aplicable a las controversias surgidas de un TI o Tratado Bilateral de Inversión, en adelante TBI, será principalmente el mismo tratado de inversión. Aun en el caso de que el TI con el cual se está presentando el reclamo no contenga una cláusula específica de derecho aplicable ${ }^{9}$, ya que incluso en esos casos los inversionistas presentan sus reclamos bajo las disposiciones del TI haciendo necesario resolver los reclamos según las disposiciones del mismo TI, y sobre la base del Derecho Internacional. Por eso un tribunal arbitral no puede sino aplicar el TI y las normas de Derecho Internacional relevantes a la disputa ${ }^{10}$.

Zachary Douglas afirma también que el derecho aplicable al fondo de la controversia en materia de inversiones será el mismo TI, o más específicamente el derecho aplicable al fondo será el estándar de trato a la inversión contenido en la disposición del TI que es la base del reclamo ${ }^{11}$ formulado por el inversionista.

151, 157, 164, 171 y 176. Así como, el caso Amco v. Indonesia, Annulment Decision, 16 May 1986, 1 ICSID Reports 509 at $\mathbf{9}$ 20-2, y el caso de Aucoven v. Venezuela, Award, 23 September 2003, at 9102.

7 Parra, Alberto, obr. cit., p. 6. Véase, también, la decisión del Comité ad hoc del caso Amco Asia Corp. v. Indonesia que destacó que bajo la segunda parte del artículo 42(1) "autoriza a un Tribunal CIADI a aplicar reglas del Derecho Internacional únicamente para llenar una laguna en el derecho aplicable local y asegurar la preferencia de las normas internacionales cuando las normas del derecho local está en colisión con esas normas" (Amco Asia Corp. v. Republic of Indonesia, Ad Hoc Comitee Decision of May 16, 1986, 1 ICSID Rep. 509, 515 (1993).

8 Debemos mencionar que los TI cuyas disposiciones que contengan una cláusula paraguas traerá a la esfera de controversias bajo el Tratado a algo que en principio es un reclamo contractual, no obstante esto, no implica que el reclamo contractual en esa situación se transforme un reclamo de Derecho Internacional, ni que el derecho aplicable será el Tratado de inversión, en esos casos el derecho aplicable es el mismo contrato o la ley que hayan seleccionado las partes en la controversia. Esto en virtud de que la Cláusula paraguas opera como una garantía o mecanismo adicional para asegurar el cumplimiento del contrato, pero no tiene por finalidad el transformar los reclamos contractuales. Sobre este punto, véase en el mismo sentido y mayor detalle: Crawford, James, Treaty and Contract in Investment Arbitration. The 22nd Freshfields Lecture on International Arbitration London, [on line] 29 november 2007, [consultado 10 de diciembre de 2009] pp. 18-21. Disponible en la World Wide Web: www.lcil. cam.ac.uk/.../lectures/.../Freshfields\%20Lecture\%202007.pdf

10 Spiermann, Ole, obr. cit., p. 108.

11 Zachary, Douglas, The International Law of Investment Claims, Cambridge University Press, First edition, 2009, p. 81. 
No obstante lo anterior, esto no significa que el TI se aplicará exclusivamente o será la única fuente, ya que como mencionan Newcombe, Andrew y Paradell, Lluís existen cuatros fuentes de reglas relevantes aplicables a la resolución de las controversias de Inversiones ${ }^{12}$ (surgidos de un $\mathrm{TI}$ ). Estas son: el tratado de inversión que contiene las protecciones cuya vulneración es alegada por el inversionista, requiriendo necesariamente que sus disposiciones sean aplicadas; la segunda fuente es el Derecho Internacional al ser el TI es un Tratado Internacional y como tal está gobernado por el Derecho Internacional ${ }^{13}$; la tercera fuente serían ciertos términos "subyacentes relacionados a un contrato de inversión"14; la cuarta y última fuente de derecho aplicable, es el derecho local del Estado en donde se realizó la inversión, cuyas normas jugarán un papel al momento de analizar los "derechos comerciales y de propiedad que constituyen la inversión protegida"15.

En términos bastante similares el tribunal del caso LG\&E contra Argentina, consideró que el derecho aplicable en ese caso sería "en primer lugar, el Tratado Bilateral, en segundo lugar, y a falta de regulaciones expresas de este último, aplicará el Derecho internacional general $y$, en tercer lugar, el Derecho interno argentino, especialmente el (...) dictado para el sector del gas natural. Este último se aplicará por la importancia que reviste para la determinación de la posible responsabilidad de la República Argentina(...)"16.

\section{El rol del TRATADO de INVERSIÓN}

Como se mencionó anteriormente, el principal instrumento aplicable al fondo de una controversia surgida entre el Estado receptor y el Inversionista será el Tratado de inversión, concretamente, las protecciones sustantivas contenidas en el texto del TI que los inversionistas alegan han sido vulneradas por el Estado receptor.

Esta postura encuentra respaldo en la decisión del comité ad hoc del caso CAA y Vivendi contra Argentina cuando sostuvo que:

2 Newcombe, Andrew; Paradell, Lluís, Law and Practice of Investment Treaties: Standards of Treatment. Published by Kluwer Law International. 2009, pp. 86-88.

13 Las normas del Derecho Internacional deben ser aplicadas de manera suplementaria por los principios y reglas generales del Derecho Internacional.

14 Newcombe, Andrew; Paradell, Lluís, obr. cit., pp. 86-88. En términos similares véase Schereuer y Dolzer, para quienes el derecho sustantivo de protección a los inversionistas consiste en "el derecho de los tratados, contenido en su mayoría en los TBIs, pero también tratados multilaterales como el NAFTA (...), así como también derecho internacional consuetudinario (...) y el derecho local del estado receptor de la inversión". Dolzer, Rudolph; Schreuer, Cristoph, Principles of International Investment Law. Oxford University Press. p. 265.

15 Newcombe, Andrew; Paradell, Lluís, obr. cit., pp. 86-88.

16 LG\&E v. Argentina, Decisión sobre Responsabilidad. Octubre 3, 2006. ๆ 99. 
"Si ha existido un reclamo del TBI y si ha existido un reclamo del contrato son cuestiones diferentes. Cada uno de estos reclamos se determinará por referencia a su propio derecho aplicable, en el caso del TBI, por el Derecho Internacional; en el caso del Contrato de Concesión, por el derecho del contrato"17.

Esto es así, porque los arbitrajes surgidos del TI están "motivados en los derechos del inversionista y las obligaciones del Estado receptor conferidos (...) [en el tratado de inversión] (...) Consecuentemente, los estándares sustantivos del [Tratado de inversión] son lex specialis y la fuente primaria aplicable"18 a la controversia.

Por esa razón, cuando la "reclamación (...) ha sido presentada con arreglo al TBI, (...) la consulta del Tribunal se rige por el Convenio CIADI [o las reglas del Centro de Arbitraje al cual se sometió la controversia], por el TBI y por el Derecho Internacional aplicable"19.

En términos parecidos, el comité ad hoc de anulación del caso MTD contra Chile sostuvo que la "lex causae" es el Derecho Internacional en un "caso basado en el incumplimiento del Tratado de Inversiones" 20.

Posición que también es compartida por el arquitecto del Convenio CIADI, Aron Broches, al indicar que:

"un Tribunal CIADI aplicará Derecho Internacional cuando el problema esté directamente regulado por el Derecho Internacional, [como ocurre cuando hay un] (...) [TI] entre el Estado que es parte en la controversia y el Estado cuyo nacional es la otra parte en la controversia" 21.

No debe sorprender, entonces, que la fuente primaria de derecho en una controversia surgida de un Tratado de inversión sea ese mismo instrumento. Tampoco debe sorprender que:

"los Tribunales arbitrales los apliquen de manera directa, además, la interacción con el Derecho Internacional para la protección de extranjeros y la implicación

17 Compañía de Aguas del Aconquija S.A. and Vivendi Universal S.A. v. Argentina, Decision on Annulment, ICSID Case No ARB/97/3, IIC 70 (2002) 3 July 2002. I 96.

18 Newcombe, Andrew; Paradell, Lluís, obr. cit., p. 109

19 Azurix Corp. v. Argentina, Laudo, ICSID Case N ARB/01/12, IIC 24 (2006) 14 julio 2006. ๆ 67.

20 MTD Equity Sdn Bhd and MTD Chile S.A. v. Chile, Decision on Annulment, ICSID Case N ${ }^{\circ}$ ARB/01/7, IIC 177 (2007) 16 february 2007. I 61.

21 Aparece en Spiermann, Ole, obr. cit., p. 108. Pensemos el caso de un TI entre el Estado A y el Estado B, el Estado B es demandado por un nacional (inversionista) del Estado A, en esos casos, según Broches, se aplicaría el Derecho Internacional de manera directa por los Tribunales CIADI. 
del principio pacta Sunt Servanda22"; nos dará como resultado que los Tribunales también apliquen normas o principios del Derecho Internacional que resulten relevantes al $\mathrm{Caso}^{23}$.

De todo lo anterior se desprende que los reclamos surgidos bajo el Tratado de inversión "debe ser decidido con las provisiones del TBI [o del TI] y del Derecho Internacional como (...) derecho aplicable"24.

Por esto Spiermann afirma que el derecho local "será confinado a ciertas cuestiones preliminares e incidentales (como preguntas sobre hechos, deben ser resueltas aun si la jurisdicción es restringida a reclamos del tratado)"25.

\section{El rol del derecho local}

Si bien el TI será la fuente principal a ser aplicada por el Tribunal para resolver la controversia, este no podría ser aplicado en solitario o de manera autónoma, ya que "no define exhaustivamente todos los aspectos de la relación inversionista-Estado y contiene las obligaciones básicas del Estado" ${ }^{26}$. De ahí que en ciertas ocasiones otras fuentes resultan relevantes en la disputa, como sería el caso del derecho local del Estado receptor ${ }^{27}$.

Uno de los casos en los que el derecho local es relevante para la controversia, lo tenemos cuando es necesario examinar "la existencia de la inversión, [misma que] (...) se debe al derecho del territorio en el cual dicho bien es mantenido" ${ }^{28}$. Sin que

22 Ibid. p. 108.

23 Véase, por ejemplo, las decisiones de estos Tribunales, entre otros: Wena v. Egypt, Annulment Decision, 5 February 2002, 6 ICSID Reports 129 at 9 52-3 See also Wena v. Egypt, Award, 8 December 2000, 6 ICSID Reports 89 at 118, AAP v. Sri Lanka, Award, 27 June 1990, 4 ICSID Reports 250 at 9 114, Santa Elena v. Costa Rica, Award, 17 Feburary 2000, 5 ICSID Reports 157 at 9 104, Metalclad v. Mexico, Award, 30 August 2000, 5 ICSID Reports 212 at 128 and Middle East Cement v. Egypt, Award, 12 April 2002, 7 ICSID Reports 178 at 9174.

24 Parra, Alberto, obr. cit., p. 9.

25 Aparece en Spiermann, Ole, obr. cit., p. 108.

26 Newcombe, Andrew; Paradell, Lluís, obr. cit., p. 91.

27 Sobre este punto, Schreuer resalta que el derecho local regula cuestiones relacionadas con aspectos "técnicos como admisión, licencias, relaciones laborales, régimen impositivo", entre otros. Schreuer, Christoph, International and Domestic Law in Investment Disputes: The Case of ICSID /en/ Austrian Review of International and European Law, 1996, p. 89.

${ }_{28}$ Newcombe, Andrew; Paradell, Lluís, obr. cit., pp. 91-92. Este enfoque es el que adoptó el Tribunal del Caso EnCana Corporation contra Ecuador (donde el inversionista sostenía que se había producido una expropiación debido a la supuesta no devolución por parte de la Administración Tributaria Ecuatoriana (SRI) del Impuesto al Valor Agregado al que consideraba tenía derecho el inversionista) cuando dijo que: "para que haya existido una expropiación de una inversión (...) los derechos afectados deben 
esto signifique "que el derecho local determina o limita lo que califica como una inversión bajo propósitos del [TI], [solamente] la existencia del bien que puede calificar como inversión bajo [el TI], así la validez de la inversión, es cuestión del derecho local" 29 .

Un ejemplo de este enfoque lo encontramos en el caso del tribunal Fraport contra Filipinas donde sostuvo que:

"La operación efectiva del régimen del TBI parecería requerir que (...) si al inicio de la inversión, se cumplió con el derecho del estado receptor [se adquirió un derecho de propiedad sobre la inversión], alegaciones por parte del Estado receptor sobre violaciones a su derecho local durante el curso de la inversión [después de realizada esta], puede ser una defensa a un reclamo sustantivo de violación del TBI"30.

O en otras palabras, una vez "se ha reconocido un derecho in rem de acuerdo al derecho local del Estado receptor, y se determina que cae dentro de la definición de inversión [contenida en el TI] la protección brindada por el Tratado de Inversión entra en operación" ${ }^{\prime 31}$.

A más de esto, Newcombe y Paradell mencionan que el derecho local resultaría relevante, para constatar "si la inversión es mantenida en el territorio del Estado receptor, la naturaleza y el alcance de los derechos sobre la inversión (...) las condiciones (...) para la operación de la inversión, la naturaleza y alcance de las medidas del gobierno supuestamente en incumplimiento del Tratado de inversión" ${ }^{\prime 32}$.

Por otra parte, el derecho local aplicable al caso será el derecho vigente al momento en que se realizó la inversión, así como el derecho posterior o las modificaciones que introduzca el Estado. No obstante, lo más usual es que los cambios en la legislación o derecho local sean relevantes en la disputa por su supuesto efecto perjudicial o dañino para la inversión, y constituyan la base del reclamo del inversionista, pensemos en el supuesto en que se terminen contratos, excluya compensación en ciertos casos, etc. En dichas situaciones el Tribunal deberá determinar la validez

existir bajo el derecho que los crea, en este caso, el derecho del Ecuador" (Resaltado mío). EnCana Corporation v. Republic of Ecuador. Merits. 12 ICSID 427. ๆ 184.

29 Newcombe, Andrew; Paradell, Lluís, obr. cit., pp. 92-98.

30 Fraport v. Philippines. Preliminary Objections. \ 345.

31 Zachary, Douglas, obr. cit., p. 53.

32 Newcombe, Andrew; Paradell, Lluís, obr. cit., p. 95. Esta opinión fue señalada por el Tribunal del Caso MTD contra Chile cuando resaltó que "el incumplimiento de una obligación internacional deberá ser, por definición, juzgada en términos de Derecho Internacional. Para establecer los hechos de dicho incumplimiento, puede resultar necesario tomar en cuenta el derecho local" MTD Equity Sdn Bhd and MTD Chile S.A. v. Chile, Award, ICSID Case No ARB/01/7, IIC 1742004) 25 May 2004 ฯ 204. 
de dicha medida o si estos cambios son un incumplimiento del Tratado de inversión según interprete el tratado de inversión y el Derecho Internacional en general ${ }^{33}$; es decir, se contrastará la compatibilidad de la medida del derecho local con las obligaciones asumidas por el Estado en el TI.

\section{Limitaciones del Derecho Local}

Como ya se mencionó en este capítulo es indudable que el derecho local será de relevancia en ciertos aspectos para poder resolver la controversia de inversiones por parte del Tribunal. Dicho esto, no podemos desconocer que ese rol o papel dependerá en gran parte del "estándar del tratado invocado por el demandante" ${ }^{34}$ y de la inversión que supuestamente resultó afectada, es decir, de qué bien o qué se está diciendo fue afectado o era la inversión en la disputa que presentó.

Otra forma en la cual el derecho local aplicable a la controversia se ve limitado es, por ejemplo, cuando el Estado receptor "tras haber formalmente, o de facto reconocido la validez de un contrato de inversión al beneficiarse de él por algún tiempo, el derecho internacional impide al Estado receptor [de la inversión] negar sin más su validez bajo el derecho local y consiguientemente escapar [o eludir] responsabilidad por su incumplimiento o terminación unilateral"35. En esos casos, el tribunal deberá determinar la validez de dicha medida o si estos cambios son un incumplimiento del Tratado de Inversión según se interprete el tratado de inversión y el Derecho Internacional.

\section{Papel del Derecho Internacional}

A pesar de que los TI son la norma principal a aplicarse para resolver las controversias, no son aplicados de forma aislada o autónoma respecto del Derecho Internacional, al no ser estos un régimen autónomo ${ }^{36}$.

33 Newcombe, Andrew; Paradell, Lluís, obr. cit., p. 98.

34 Ibid. p. 97.

35 Ibid. p. 97.

36 Este concepto puede interpretarse de distintas formas; la primera como "una subcategoría (a saber, una "forma fuerte") de lex specialis dentro de las normas relativas a la responsabilidad del Estado (...) [una suerte de] conjunto especial de normas secundarias tiene prioridad sobre las normas secundarias del derecho general aplicables a la responsabilidad del Estado". Comisión de Derecho Internacional de Naciones Unidas. A/CN.4/L.682 13 de abril de 2006. Informe del Grupo de Estudio de la Comisión de Derecho Internacional sobre la FRAGMENTACIÓN DEL DERECHO INTERNACIONAL: DIFICULTADES DERIVADAS DE LA DIVERSIFICACIÓN Y EXPANSIÓN DEL DERECHO INTERNACIONAL. KOSKENNIEMI, M. $58^{\circ}$ período de sesiones Ginebra, 1 de mayo a 9 de junio y 3 de julio a 11 de agosto de 2006. ๆ 128. 
Sobre este punto, podemos destacar que el tratado de inversión, como "lex specialis", se aplica complementado por el derecho consuetudinario internacional "cuando es necesario juzgar la responsabilidad del Estado receptor en las disputas" 37 surgidas del Tratado de inversión. Es decir, el TI deberá en ciertas ocasiones ser interpretado a la luz de la normas del derecho consuetudinario internacional cuando una materia no esté regulada de manera expresa por el TI.

Como resalta el Prof. Prosper Weil, esta tendencia de aplicar el tratado de inversión, de manera complementaria con el Derecho Internacional general, se debe a que el arbitraje de inversiones "está gobernado por el Derecho Internacional en virtud de que el TBI implícitamente o explícitamente prevé que las disputas deban ser resultas no solo en base de las provisiones del Tratado mismo, sino también (...), sobre la base de los principios y reglas del Derecho Internacional"38.

McLachlan en su libro International Investment Arbitration Substantive Principles, afirma que esta posibilidad de acudir al derecho internacional al momento de aplicar los $\mathrm{TI}$, se debe principalmente a que estos no son "regímenes autónomos. El significado de sus términos operativos debe ser informado por referencia a las reglas de derecho internacional aplicables entre las partes" ${ }^{\prime \prime}$.

La referencia al derecho internacional, según los mismos autores, traerá como consecuencia dos presunciones:

a) Una presunción negativa, según la cual "al crear obligaciones a través del tratado, la intención de las partes fue no actuar de manera inconsistente ${ }^{\prime 40}$ con las demás normas internacionales, entiéndase principios generales del derecho y obligaciones emanadas de tratados con terceros Estados.

b) La segunda presunción sería una presunción positiva que es que "las partes se refieren a los principios generales del derecho internacional en todas las formas en las que el tratado no resuelve por sí mismo en términos expresos y en una manera diferente" ${ }^{\prime \prime 1}$.

\footnotetext{
No obstante, en este trabajo se empleará "para referirse a conjuntos interrelacionados de normas primarias y secundarias, a las que a menudo se llama "sistemas" o "subsistemas" de normas que abordan un problema particular de una manera diferente a las normas del derecho general". Ibid. ๆ 128.

37 Newcombe, Andrew; Paradell, Lluís, obr. cit., pp. 98-99.

38 Ibid. pp. 98-99.

39 McLachlan, Campbell, Shore, Laurence, Weiniger, Matthew, International Investment Arbitration. Substantive Principles, Oxford University Press, 2007, p. 15.

40 Ibid. p. 15.

41 Ibid. pp. 15-23.
} 
Posición que ha encontrado gran respaldo por diversos tribunales internaciona$\mathrm{les}^{42}$, los que han resaltado y recogido la noción de que el TI es la norma primaria, y como tal debe primar o ser considerada de manera primaria por encima "la costumbre o principios generales [del derecho internacional] si estos establecen un test o regla diferente ${ }^{43 \prime}$. Un ejemplo de esto lo encontramos en la posibilidad de muchos $\mathrm{TI}$, que permiten al inversionista acudir directamente al arbitraje en caso de controversias, sin tener que agotar los recursos internos del Estado receptor como requiere el derecho internacional consuetudinario.

Esta formulación es comúnmente conocida bajo la máxima de "lex specialis derogat generali"; ha sido entendida bajo la noción de que el tratado de inversiones al ser un instrumento específicamente acordado por las partes para regular las relaciones entre estos en una determinada materia [en nuestro caso, el derecho internacional de las inversiones], debe primar y ser considerado por encima de las otras fuentes del derecho internacional ${ }^{44}$.

Sobre este mismo punto, Zachary Douglas apoya la noción que el TI no puede ser aplicado de manera aislada del resto del Derecho Internacional, y más concretamente de los principios de este último, al ser justamente el TI una "creación del Derecho Internacional" 45 , el TI "operará dentro del sistema legal internacional"46.

\section{El Principio lex Specialis}

Como se ha venido sosteniendo a lo largo de este trabajo que, el TI será la fuente principal de aplicación para la solución de la controversia en un arbitraje surgido del mismo TI, pero como se mencionó anteriormente este no se aplica de manera aislada o autónoma, sino que interactúa o aplica complementado por el Derecho Internacional (sea la costumbre internacional o a través a la referencia de los principios generales del derecho internacional), a manera de lex specialis (como norma especial

42 Sobre este punto véase el enfoque adoptado por el tribunal en el "asunto Asian Agricultural Products, Ltd (AAPL) v. Democratic Socialist Republic of Sri Lanka en su Laudo del 27 de junio de 1990, [cuando sostuvo que] "[El Tratado] no es un sistema jurídico cerrado y completo, limitado a proporcionar normas materiales sustantivas de aplicabilidad directa sino que ha de contemplarse dentro de un contexto jurídico más amplio en el que normas de otras fuentes se integran a través de métodos de incorporación implícita o por referencia directa a ciertas normas suplementarias, ya sean de naturaleza jurídica internacional, ya de derecho interno". Aparece en LG\&E v. Argentina, Decisión sobre Responsabilidad. Octubre 3, 2006. ब 97.

43 Newcombe, Andrew; Paradell, Lluís, obr. cit., p. 111.

${ }_{44} \mathrm{Al}$ respecto véase McLachlan, Campbell, Shore, Laurence, Weiniger, Matthew, obr. cit., p. 17. Donde se afirma que al ser todavía la relación entre los tratados de inversión y el derecho internacional en general... problemática requiere que en caso de conflicto entre estos el tratado debe primar como lex specialis.

45 Zachary, Douglas, obr. cit., p. 85.

46 Ibid. p. 85. 
frente a las reglas generales del Derecho Internacional); por lo que en esta sección revisamos la aplicación, características del principio de "lex specialis" y cómo deberá ser aplicado por los tribunales, al analizar un reclamo de inversiones surgidas del TI.

Como se dijo anteriormente, el principio "lex specialis" permite a los Tribunales aplicar o emplear la norma especial, en lugar de las normas generales que regulan una misma materia. Normalmente, se lo emplea para resolver conflictos normativos (pero no solo para estos casos) sino también "entre la generalidad y la particularidad de las normas en conflicto" ${ }^{\prime 4}$.

El principio de lex specialis, hace que cuando tengamos "una materia (...) regulada por una norma general y por una norma más específica, esta última (...) [prevalezca] sobre la primera" ${ }^{48}$. La relación entre normas especiales y normas generales no solo puede ser vista como una relación de conflicto, sino como una relación en que "la norma específica se debe leer e interpretar dentro de los límites o del marco de la norma general, típicamente como desarrollo, actualización o especificación técnica de la última"49.

La jurisprudencia internacional ha aplicado de manera habitual "el principio de la 'lex specialis', aunque (...) [sin haber sido] (...) desarrolla[do] demasiado" 50 por los tribunales internacionales. Pese a esto, Martti Koskenniemi en su informe para el Grupo de Estudio sobre la Fragmentación del Derecho Internacional identificó cuatro situaciones en las que el principio puede operar:

“1) Dentro de un único instrumento;

2) Entre dos instrumentos diferentes;

3) Entre una norma convencional y una norma no convencional; y

4) Entre dos normas no convencionales" ${ }^{51}$.

47 Esta tensión entre normas especiales y normas generales dentro del Derecho Internacional produjo el fenómeno que se conoce como fragmentación, y que la Comisión de Derecho Internacional "distinguió tres tipos de conflicto a saber:

a) Los conflictos entre la ley general y una interpretación particular y poco ortodoxa de la normativa general;

b) Los conflictos entre la ley general y una norma particular que pretende ser una excepción a la ley general, y

c) Los conflictos entre dos tipos de normas especiales". (Comisión de Derecho Internacional de Naciones Unidas. A/CN.4/L.682 13 de abril de 2006. Informe del Grupo de Estudio de la Comisión de Derecho Internacional sobre la FRAGMENTACIÓN DEL DERECHO INTERNACIONAL..., op. cit., 47).

48 Ibid.

49 Piénsese, por ejemplo, en el reclamo de denegación de justicia, que es una especificación de la regla del agotamiento de los recursos internos. En estas situaciones tendremos dos normas (general y específica) que apuntan hacia la misma dirección. Ibid. 56.

50 Ibid. 68.

51 Ibid. 68. 
En el caso de la aplicación del principio "lex specialis" a los TI, encontraremos que este vendrá a ser aplicado generalmente para "regular la relación entre el tratado [de inversión] (...) (lex specialis) y la costumbre (como "ley general")" 52 . Es decir, estará dentro de la tercera situación, según identificó, Martti Koskenniemi.

Un ejemplo de lo dicho en el párrafo anterior, lo encontramos en el caso de INA Corporation contra el Gobierno de la República Islámica del Irán, donde el Tribunal "no determinó el contenido preciso de la norma consuetudinaria [sobre compensación por nacionalización] pues estimó, que a los efectos de la causa (estamos ante una lex specialis en la forma del Tratado de Amistad, que en principio tiene primacía sobre las normas generales)" ${ }^{53}$ (Resaltado mío).

En iguales términos se pronunció la Corte Internacional de Justicia, en adelante, CIJ, en el caso de los "contras" (Nicaragua contra Estados Unidos) cuando afirmó que:

"En general, como las normas convencionales son lex specialis, no sería apropiado que un Estado entablara una reclamación fundado en una norma de derecho consuetudinario si, en virtud de un tratado, ya ha establecido arbitrios para el arreglo de esa reclamación" ${ }^{54}$ (Resaltado mío).

Resumiendo, podemos ver claramente que "se acepta universalmente que -aparte de la consideración del jus cogens- un tratado [de inversión] lex specialis es derecho entre las partes en derogación del derecho consuetudinario general que, en caso contrario, habría regido en sus relaciones" ${ }^{\prime 55}$.

Esta derogación mencionada en el párrafo anterior, no debería verse como un reemplazo permanente del derecho consuetudinario general, ya que el principio de 'lex specialis" únicamente indica la norma que "debe aplicarse (...) [tras lo cual] la norma especial, pasa para aplicarse en lugar de la norma general. Tal reemplazo permanece, no obstante siempre parcial. La norma más general permanece en el fondo proveyendo dirección interpretativa a la norma especial" 56 .

Villiger, Mark, Customary International Law and Treaties: a study of their interactions and interrelations with special consideration of the 1969 Vienna Convention on the Law of Treaties, Dordrecht Nijhoff, 1985, p. 161.

53 INA Corporations v. Iran, Iran-U.S. C.T.R., vol. 8, 1985-I, p. 378. Aparece en Comisión de Derecho Internacional de Naciones Unidas. A/CN.4/L.68213 de abril de 2006.Informe del Grupo de Estudio de la Comisión de Derecho Internacional sobre la FRAGMENTACIÓN DEL DERECHO INTERNACIONAL..., obr. cit., 78.

54 Actividades militares y paramilitares en y contra Nicaragua (Nicaragua c. los Estados Unidos de América) (fondo del asunto), I.C.J. Reports 1986, p. 137 (párr. 274).

55 Comisión de Derecho Internacional de Naciones Unidas. A/CN.4/L.68213 de abril de 2006. Informe del Grupo de Estudio de la Comisión de Derecho Internacional sobre la FRAGMENTACIÓN DEL DERECHO INTERNACIONAL..., obr. cit., 81.

56 Report of the Study Group of the International Law Commission, Fragmentation of International Law: 
Resulta atípico encontrar situaciones en la que la aplicación del principio "lex specialis" conlleva a una exclusión total o absoluta del derecho general consuetudinario. Como ocurrió en el caso de UPS contra Canadá, en el cual el Tribunal consideró que las reglas del capítulo 15 de NAFTA que trata sobre monopolios y empresas estatales eran "lex specialis" y se aplicaban con total independencia de los Artículos de Responsabilidad Internacional de los Estados preparados por la Comisión de Derecho Internacional de Naciones Unidas ${ }^{57}$.

\subsection{Referencia a la lex specialis}

Martti Koskenniemi, en su informe sobre Fragmentación del Derecho Internacional para el Grupo de Estudio de la Comisión de Derecho Internacional de Naciones Unidas, resalta dos "tipos de relaciones entre una norma particular y una general" o en nuestro caso entre el TI (particular o especial) y la costumbre internacional o los principios generales (norma general).

La primera de estas relaciones, considera a la norma particular como "la aplicación de una norma general en un caso concreto" ${ }^{\prime 59}$; mientras que la segunda, considera a la norma particular o especial como "una modificación, una derogación o una exclusión de una norma general"60.

De estas dos relaciones, el primer caso o referencia es interpretado como una situación que "implica la aplicación simultánea de la norma especial y la general"61.

En el presente trabajo seguiremos y emplearemos la noción de "lex specialis" que hace aplicable al principio "incluso en ausencia de un conflicto directo entre dos disposiciones y cuando ambas habrían podido aplicarse simultáneamente" ${ }^{\prime 62}$.

Difficulties Arising from the Diversification and Expansion of International Law, U.N. Doc. A/Cn.4/L.682 (Apr. 4 2006). Aparece en Kurtz, Jürgen, Adjudging the Exceptional at International Law: Security, Public Order and Financial Crisis, Jean Monnet Working Paper 06/08, 2008, p. 35.

57 United Postal Service of America Inc. v. Canada, ICSID Arbitration, Award on the Merits (May 24, 2007). I 59-62. Aparece en Kurtz, Jürgen, obr. cit., p. 37.

58 Comisión de Derecho Internacional de Naciones Unidas. A/CN.4/L.68213 de abril de 2006. Informe del Grupo de Estudio de la Comisión de Derecho Internacional sobre la FRAGMENTACIÓN DEL DERECHO INTERNACIONAL..., obr. cit., 88.

59 lbid. 88

$60 \quad$ lbid. 88.

61 Ibid. 88.

62 Esto en consideración de que la mayoría de las veces "no es necesario (no es posible, de hecho) decidir si la lex specialis se utiliza como "criterio interpretativo" o como "técnica de solución de conflictos", si se limita a "dar aplicación" a ciertas normas de carácter más general o si se aparta de ellas". Comisión de Derecho Internacional de Naciones Unidas. A/CN.4/L.682 13 de abril de 2006. Informe del Grupo de Estudio de la Comisión de Derecho Internacional sobre la FRAGMENTACIÓN DEL DERECHO INTERNACIONAL..., obr. cit., 91. 


\subsection{Aplicación del principio de lex specialis}

\subsubsection{LEX specialis como elaboración de lege generali}

La primera aplicación del principio lo encontramos cuando, una norma es "lex specialis", en relación con otra norma como una "aplicación, actualización o desarrollo de ella o, lo que es lo mismo, como su suplemento, como un indicador de instrucciones de lo que una norma general exige en un caso particular" ${ }^{\prime \prime 3}$.

Sobre este punto, el Tribunal de Reclamaciones Irán-Estados Unidos declaró en el caso Amocco International Finance Corporation c. el Irán que:

"Como lex specialis, (...) el Tratado prevalece sobre la lex generalis, es decir, el Derecho Internacional consuetudinario. No obstante, ello no significa que este sea irrelevante (...) las normas del derecho consuetudinario pueden ser útiles para colmar las posibles lagunas del Tratado, para esclarecer el significado de ciertos términos que no se definen en su texto o, con carácter más general, para facilitar la interpretación y la aplicación de sus disposiciones" ${ }^{64}$.

El que una norma de Derecho Internacional consuetudinario sirva para dar significado a la norma especial, fue el método empleado por la CIJ, en su opinión consultiva emitida acerca de la Legalidad de la amenaza o el empleo de armas nucleares. En donde, para poder determinar lo que se entendía por privación arbitraria de vida, debía aplicar la norma especializada, o la más específica, como era la contenida en el Derecho Internacional Humanitario o derecho de guerra ${ }^{65}$.

\subsubsection{LEX specialis como excepción a la norma general}

La segunda forma en la que se puede aplicar o podemos encontrar referencia al principio de "lex specialis", es a través de la voluntad de los Estados de apartarse o derogar la aplicación de determinadas normas del Derecho Consuetudinario general, no obstante esto, la norma excluida que parecería desaparecer totalmente no lo hace, más bien, tiene una aplicación residual, puesto que la norma especial desplaza a la norma general respecto a un aspecto en particular ${ }^{66}$.

63 Ibid. 98. Caso en el que se encontrará el TI en la mayoría de situaciones, actuando como la norma lex specialis pero en algunos casos como es el de la Responsabilidad del Estado, el derecho consuetudinario es de gran utilidad para aplicar o efectivizar las normas del Tratado.

64 AMOCO International Finance Corporation c. el Irán, Irán-U.S. C.T.R., 1987-II vol. 15, p. 222. 123.

65 Pese a que en este caso la Corte lo analizó a la luz de las Convenciones de Ginebra, gran parte de dichas disposiciones han adquirido o tienen el carácter de norma consuetudinaria del Derecho Internacional. Legalidad de la amenaza o el empleo de armas nucleares, Opinión consultiva I.C.J. Reports 1996, p. 240, ब 25.

66 Comisión de Derecho Internacional de Naciones Unidas. A/CN.4/L.682 13 de abril de 2006. Informe 
Tenemos un ejemplo de este caso en los TI cuando las partes han decidido no requerir que se agoten los recursos internos previo al sometimiento de una controversia a arbitraje internacional por el inversionista. Sin que esto implique que la regla del agotamiento de recursos internos haya sido derogada en general, o no tendrá aplicación alguna en el Tratado, por ejemplo esta seguirá siendo aplicable o determinante para que el inversionista logre demostrar que se ha producido una denegación de justicia.

\subsection{Prohibición de la lex specialis}

Como es sabido, la mayor parte del Derecho Internacional general puede derogarse mediante "lex specialis". Sin embargo, de manera excepcional la naturaleza de ciertas normas generales prohíbe expresamente cualquier desviación o derogación. Ese es el caso de las normas "jus cogens", las que primarán y no se considerarán derogadas, aun con el consentimiento de los Estados ${ }^{67}$.

\section{Conclusiones}

Para finalizar, podemos decir que en principio el derecho aplicable al fondo de la controversia surgida de un Tratado de Inversión, variará de la fuente o del instrumento bajo el cual se origine la misma. Es decir, bajo un contrato de inversión, bajo una ley local de inversión, o como en el caso que hemos analizado, bajo un Tratado de Inversión.

En este último caso podríamos decir que la tendencia jurisprudencial de los tribunales de arbitraje de inversiones apunta a que la principal norma a ser aplicada al fondo de la controversia, sea el mismo Tratado de Inversión. Ahora bien, esto sin perjuicio, como hemos visto a lo largo de este trabajo, que el derecho local tendrá o deberá ser aplicado en algunas situaciones (ej: nacionalidad de la compañía, determinación de derecho de propiedad, etc.); o como ya se mencionó, para analizar el efecto que tuvo una medida legislativa en la inversión.

Lo mismo podemos decir del Derecho Internacional que en muchos casos será de aplicación por referencia misma del texto del Tratado de Inversión (ej.: cuando se requiere de la interpretación de un artículo del Tratado de Inversión en relación o de acuerdo a los principios generales del Derecho Internacional). Debido a que el mismo Tratado integra a esas fuentes "a través de métodos de incorporación implícitos o

del Grupo de Estudio de la Comisión de Derecho Internacional sobre la FRAGMENTACIÓN DEL DERECHO INTERNACIONAL..., obr. cit., 104.

67 Ibid. 108-109. 
por referencia directa"68, o por referencia implícita como ocurre cuando el TI no regula de manera expresa una materia como en lo referente a la Responsabilidad Internacional del Estado o qué actos o conductas serán atribuibles a este para determinar su responsabilidad.

Por lo tanto, podemos decir que el derecho aplicable al fondo en una controversia surgida de un TI será "en primer lugar, el Tratado Bilateral, en segundo lugar, y a falta de regulaciones expresas de este último, aplicará el Derecho internacional general y, en tercer lugar, el Derecho interno" ${ }^{\prime 69}$, o derecho local.

\section{Bibliografía}

Parra, Alberto, Applicable Law in Investor- State Arbitration,Transnational Dispute Management, [on line], vol. 6, issue 1, marzo, 2009 [consultado 30 de noviembre de 2009]. Disponible en la World Wide Web: www.transnational-disputemanagement.com

Crawford, James, Treaty and Contract in Investment Arbitration. The 22nd Freshfields Lecture on International Arbitration London, [on line] 29 November 2007, [Consultado 10 de diciembre de 2009] pp. 18-21. Disponible en la World Wide Web: www.Icil.cam.ac.uk/.../lectures/.../Freshfields\%20Lecture\%202007.pdf

Spiermann, Ole, Chapter 3 Applicable Law, The Oxford Handbook of International Investment Law, Edited by Muchlinski, p. \& Others, Nueva York, Oxford University Press, 2008.

Zachary, Douglas, The International Law of Investment Claims, Cambridge University Press, First Edition, 2009.

Newcombe, Andrew; Paradell, Lluís, Law and Practice of Investment Treaties: Standards of Treatment. Published by Kluwer Law International. 2009.

Mclachlan, Campbell; Shore, Laurence; Weiniger, Matthew, International Investment Arbitration. Substantive Principles, Oxford University Press, 2007.

Villiger, Mark, Customary International Law and Treaties: a study of their interactions and interrelations with special consideration of the 1969 Vienna Convention on the Law of Treaties, Dordrecht Nijhoff, 1985.

Kurtz, Jürgen, Adjudging the Exceptional at International Law: Security, Public Order and Financial Crisis, Jean Monnet Working Paper 06/08, 2008.

68 AAP v. Sri Lanka, Award, 27 June 1990, 4 ICSID Reports 250. ๆ 21.

69 LG\&E v. Argentina, Decisión sobre Responsabilidad. Octubre 3,2006. ๆ 99. Adicionalmente, véase en el mismo sentido: Wena Hotels Limited. v. Egypt (Award, 8 Dec. 2000. ๆ 78-79.; Middle East Cement Shipping and Handling Co. S.A. v. Egypt. ๆ 87. 
DERECHO APLICABLE AL FONDO DE LA CONTROVERSIA EN ARBITRAJES...

SChreuer, Christoph, International and Domestic Law in Investment Disputes: The Case of ICSID /en/ Austrian Review of International and European Law, 1996.

Dolzer, Rudolph; Schreuer, Cristoph, Principles of International Investment Law, Oxford University Press, 2008. 